\title{
A computational approach for fatigue crack propagation in ship structures under random sequence of clustered loading
}

\author{
T. Okawa $\cdot$ Y. Sumi
}

Received: 27 September 2007/ Accepted: 24 April 2008

(C) JASNAOE 2008

\begin{abstract}
The authors have developed a simulation program, CP-System, for multiple cracks propagating in a three-dimensional stiffened panel structure, where throughthe-thickness crack propagation is formulated as a twodimensional in-plane problem, and the crack propagation behavior is simulated by step-by-step finite element analyses. In order to evaluate the fatigue lives of marine structures accurately, it is necessary to take into account the load histories induced by sea waves, which may be composed of a random sequence of certain clustered loads with variable stress range. In the proposed crack growth model, the crack opening and closure behavior is simulated by using the modified strip yielding model, and the effective tensile plastic stress intensity range, $\Delta K_{\mathrm{RP}}$, is calculated by considering the contact of plastic wake along the crack surfaces. The adequacy of the proposed crack growth model is examined by comparison with fatigue tests under non-constant-amplitude loading. The usefulness of the developed method is demonstrated for a ship structural detail under certain simulated load sequences. It is shown that the fatigue crack growth of a ship structure is significantly retarded due to the load interaction effects, so that the conventional method for fatigue life assessment may predict a relatively conservative fatigue life of a structure.
\end{abstract}

\section{T. Okawa}

Steel Products Lab.-II, Steel Research Laboratories,

Nippon Steel Corporation, 20-1 Shintomi, Futtsu,

Chiba 293-8511, Japan

Y. Sumi $(\bowtie)$

Department of Systems Design for Ocean-Space,

Yokohama National University, 79-5 Tokiwadai,

Hodogaya-ku, Yokohama 240-8501, Japan

e-mail: sumi@ynu.ac.jp
Keywords Fatigue crack propagation - Ship structures · Clustered random loading - Plastic stress intensity range

\section{Introduction}

In ship structures, fatigue cracks are usually detected by a surveyor by visual inspection. Although it is preferable to detect fatigue cracks at an early stage, small cracks such as those illustrated in Fig. 1a may sometimes be overlooked because of poor accessibly and visibility. In contrast, longer fatigue cracks such as those in Fig. $1 \mathrm{~b}$ and $\mathrm{c}$ may be easily detected by visual inspection, but their remaining lives generally make up just a few percent of their total life. If one can utilize several favorable effects to retard the propagation rate so as to avoid hazardous crack propagation, a rational fatigue crack management as illustrated in Fig. 2 could be applied, where the fatigue crack propagation behavior should be predicted accurately, and fatigue cracks of visible size are inspected at least twice during the service life [1-3].

In our previous studies, Sumi and associates have developed a simulation program, CP-System, for crack path prediction and assessment of remaining life of fatigue crack propagation in three-dimensional welded structures [1-7]. In the simulation program, through-the-thickness crack propagation is formulated as a two-dimensional in-plane problem, and the crack propagation behavior is simulated by step-by-step finite element analyses. In order to simulate realistic fatigue crack propagation in large-scale structures, the following factors should be considered:

- geometries of structural details

- actual boundary conditions

- load shedding during crack propagation 


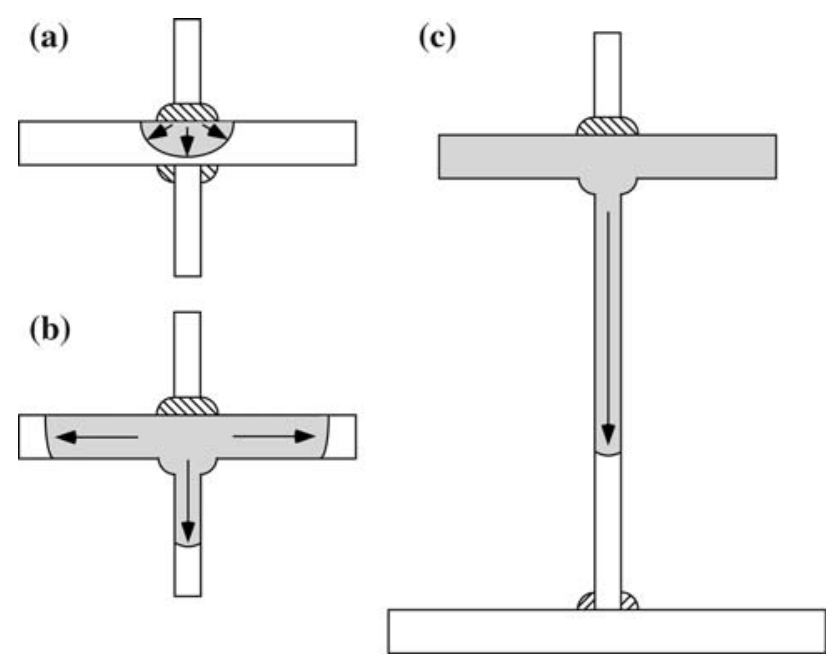

Fig. 1 Fatigue crack propagation in a longitudinal stiffener: a surface crack at the weld toe, $\mathbf{b}$ through-the-thickness crack in the face-plate and the web-plate, and $\mathbf{c}$ through-the-thickness crack in the web-plate

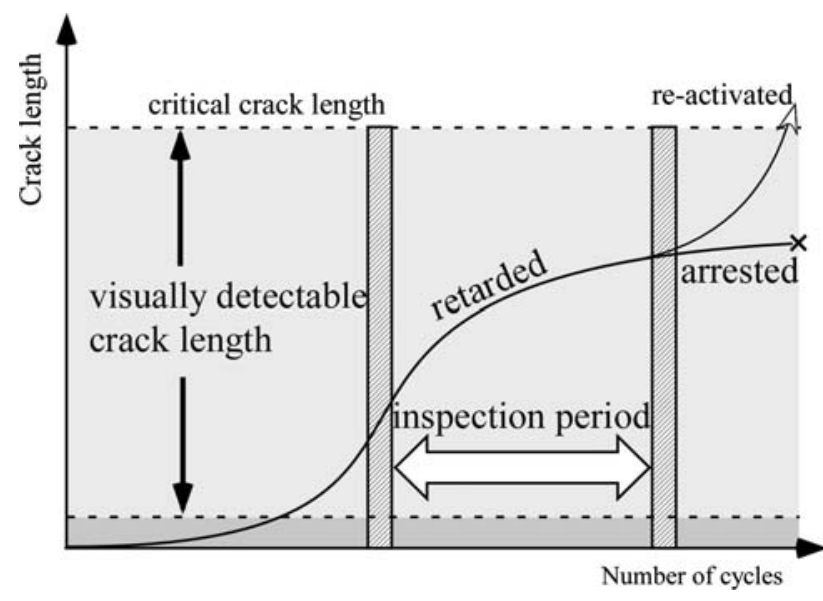

Fig. 2 Proposed concept of fatigue crack management in a welded structure

- simultaneous propagation of multiple cracks

- welding residual stresses

- effects of load sequences

In order to simulate the retardation and acceleration effects of fatigue crack growth precisely under the random load sequences induced by sea waves, a crack opening and closure model is incorporated in the present study. In the crack opening and closure model, in order to describe the plastic deformation ahead of the crack tip and the plastic wake on the crack surfaces, a number of bar elements are distributed based on the crack opening displacement evaluated by a strip yielding model, which was originally proposed by Newman [8] and Toyosada et al. [9-11]. The effective tensile yielding stress intensity range, $\Delta K_{\mathrm{RP}}$, which precisely corresponds to the cyclic tensile plastic deformation ahead of the crack tip [9-11], is calculated by considering the contact of the plastic wake along the crack surfaces.

Furthermore, the adequacy of the proposed crack growth model is examined by comparison with fatigue tests under nonconstant loading. The proposed simulation method is applied to the fatigue crack propagation in a ship structure subjected to water pressure, where the time history of the water pressure during ship sailing is simulated by the so-called storm model [12, 13], which is composed of a random sequence of clustered loadings. The results obtained by the proposed method are compared with those obtained by using the conventional crack growth equation. Fatigue crack growth is also investigated by using an equivalent load range and gradually increasing load range. It is shown that the fatigue crack growth of a ship structure is significantly retarded due to load interaction effects, so that the conventional method for fatigue life assessment may predict a rather conservative fatigue life of a structure.

\section{Multiple cracks simultaneously propagating in a three-dimensional stiffened structure}

Let us consider a thin-plate structure as shown in Fig. 3, which consists of thin plates containing multiple cracks. The structure is divided into $M$ subdomains, $\Omega_{l}$ $(l=1, \ldots, M)$, in which there exists no more than one crack tip. An orthogonal coordinate system is defined in each subdomain. Body force, $f_{i}^{l}$, is prescribed in the subdomain $\Omega_{l}$. Surface traction, $t_{i}^{l}$, is prescribed on the outer boundary, $S_{t}^{l}$, and on the crack surface, $S_{C}^{l \pm}$. Surface displacement, $v_{i}^{l}$, is prescribed on the outer boundary $S_{u}^{l}$. The boundary of the subdomain $\Omega_{l}$ is denoted by $\Gamma_{l}$ and the interface between subdomain $\Omega_{l}$ and the adjacent subdomain $\Omega_{n}$ is denoted by $\Gamma_{l} \cap \Gamma_{n}$.

The simulation program was developed in order to deal with multiple cracks propagating in a three-dimensional structure. The main procedure of the simulation is summarized as follows (see Fig. 4);

1. the finite element mesh is automatically generated by an advanced paving method [14] in each crack propagating domain,

2. the surrounding three-dimensional structures are modeled by a general-purpose program and their stiffness and load vectors are condensed along the crack propagating domain using the superelement technique [1],

3. stress field parameters near each crack tip are calculated by the method of superposition of analytical and finite element solutions [15], 
4. crack paths are predicted by the first-order perturbation solution $[16,17]$ with the use of the local symmetry criterion [18], where the interaction effects of the simultaneous propagation of multiple cracks is taken into consideration [3, 7],

5. extensional lengths of cracks are calculated based on a conventional crack growth model [19], or the present precise crack opening and closure simulation model,

6. all cracks are extended along the predicted crack paths,

7. go back to step 1 to continue the simulation.

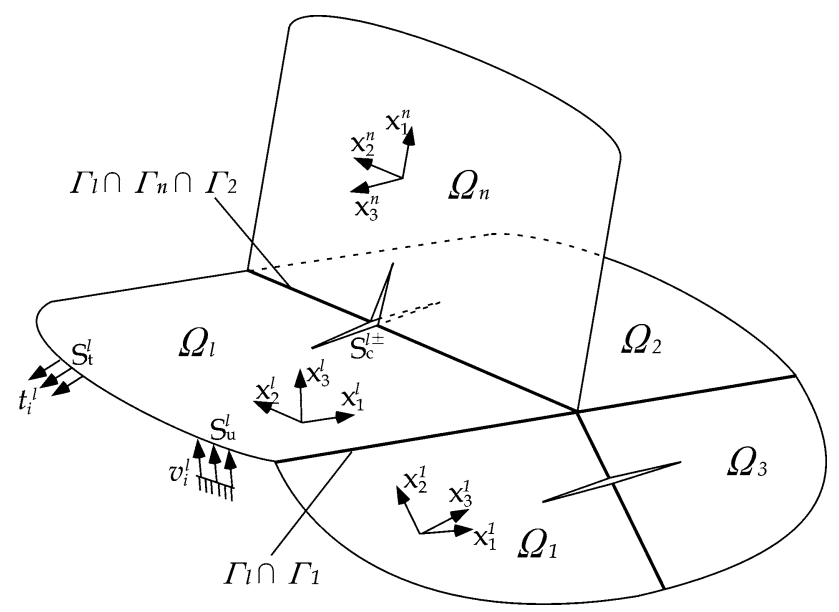

Fig. 3 Cracks in a three-dimensional thin-plate structure

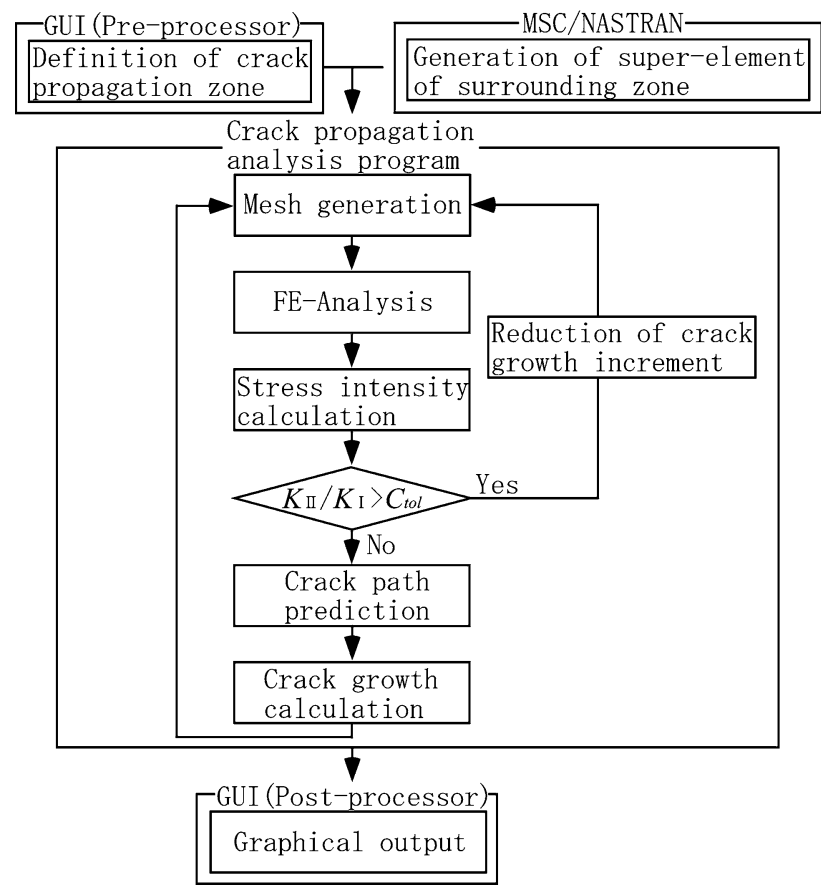

Fig. 4 Flowchart of the CP-System

\section{Simple crack growth model}

As mentioned in the previous section, we shall use two kinds of crack growth models. As a conventional model, we shall use the following crack growth law [19];

$\mathrm{d} a / \mathrm{d} N=C\left\{(U \times \Delta K)^{m}-\left(\Delta K_{\mathrm{eff}}\right)_{\mathrm{th}}^{m}\right\}$,

where $\Delta K$ is the stress intensity range, $C, m$ and $\left(\Delta K_{\text {eff }}\right)_{\text {th }}$ are the material constants, and $U$ is the effective crack opening ratio given by

$U= \begin{cases}1 /(1.5-R) & (-\infty \leq R \leq 0.5) \\ 1 & (0.5 \leq R \leq 1),\end{cases}$

where $R$ is the stress ratio. It should be noted that the retardation and acceleration effects of fatigue crack propagation induced by load sequences cannot be considered by this simple crack growth model.

\section{Crack opening and closure simulation model}

\subsection{Stress field near a crack tip}

The second crack growth model is based on the crack opening and closure simulation by using the modified strip yielding model. An orthogonal coordinate system $(x, y)$ is defined in such a way that its origin is located at the crack tip and the $x$-axis is directed along with the tangent at the crack tip (Fig. 5). The stress field ahead of the crack tip is asymptotically expressed as

$$
\begin{aligned}
\sigma_{x}(x, 0) & =\frac{k_{\mathrm{I}}}{\sqrt{2 \pi x}}+T+b_{\mathrm{I}} \sqrt{\frac{x}{2 \pi}}+O(x), \\
\sigma_{y}(x, 0) & =\frac{k_{\mathrm{I}}}{\sqrt{2 \pi x}}+b_{\mathrm{I}} \sqrt{\frac{x}{2 \pi}}+O(x), \\
\tau_{x y}(x, 0) & =\frac{k_{\mathrm{II}}}{\sqrt{2 \pi x}}+b_{\mathrm{II}} \sqrt{\frac{x}{2 \pi}}+O(x),
\end{aligned}
$$

where $k_{\mathrm{I}}$ and $k_{\mathrm{II}}$ are the stress intensity factors, $T$ is the constant stress acting parallel to the $x$-axis, and $b_{\mathrm{I}}$ and $b_{\mathrm{II}}$ are the higher-order stress field coefficients [16, 17]. These crack tip stress field parameters can be evaluated by finite

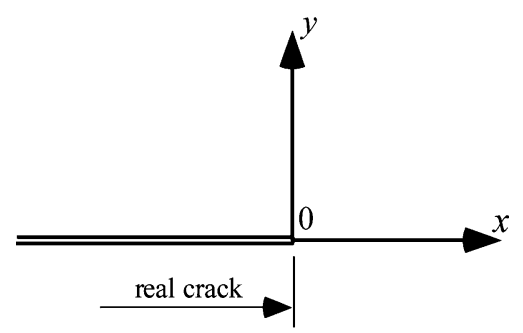

Fig. 5 Crack tip coordinate system 
element analyses. In the following formulation, the crack is modeled by a semi-infinite crack having the same crack tip stress field expressed by Eq. 3, because the relevant cyclic plastic deformation zone is assumed to be small compared with the global geometry of a crack.

\subsection{Crack tip opening and closure simulation}

In Fig. 6, the crack opening and closure model proposed in this study is schematically illustrated, where bar elements of the elastic-perfectly plastic solid are connected on the crack surfaces based on the crack opening displacement calculated by a strip yielding model. The crack opening and closure model utilizing the strip yielding model was originally proposed by Newman [8] and Toyosada et al.

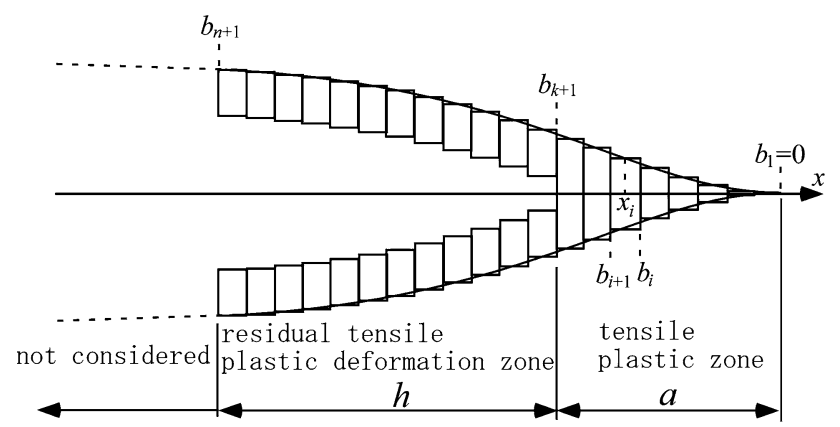

Fig. 6 Schematic illustration of the crack opening and closure model
[9-11]. Their models are only applicable to simple-shaped geometries so that further development is necessary to analyze crack propagation in ship structural details. In the present study, a new crack opening and closure model is proposed based on [9-11], where the crack opening and closure behavior is described utilizing the crack tip stress field parameters evaluated by finite element analyses so as to combine it with CP-System. As shown in Fig. 6, $n$ is the total number of the bar elements, and $k$ is the number of bar element in the plastic zone. The $i$ th bar element is located at $\left[b_{i}\right.$ and $\left.b_{i+1}\right]$, and $x_{i}$ is the mid-point of the bar element.

When the crack is subjected to the maximum load, a tensile plastic zone is generated at the crack tip, as illustrated in Fig. 7a, where $a$ is the plastic zone length, $\sigma_{\mathrm{Y}}$ is the yield stress and $\lambda$ is the plastic constraint factor. This problem can be considered as a superposition of the problems illustrated in Fig. $7 \mathrm{~b}$ and c, where Fig. 7b shows the semi-infinite crack having stress intensity factor, $\widehat{k}_{\max }$, and Fig. 7c shows the semi-infinite crack subjected to closure stress, $\lambda \sigma_{\mathrm{Y}}$, at the crack tip. Based on Sumi et al. [16], the stress intensity factor, $\widehat{k}_{\max }$, is given by

$\widehat{k}_{\max }=k_{\max }+\left\{b_{\max } / 2+\bar{k}_{\max }\right\} a$,

at the hypothetical crack tip, while $k_{\max }$ and $b_{\max }$ are the crack tip stress parameters corresponding to the maximum load at the real crack tip. The parameter, $\widehat{k}_{\max }$, represents the effect of the finite boundary, which is obtained by analyzing

Fig. 7 Superposition at the maximum load: a original problem, b semi-infinite crack having stress intensity factor, $\widehat{k}_{\max }$, and $\mathbf{c}$ Semi-infinite crack subjected to closure stress, $\lambda \sigma_{\mathrm{Y}}$, at the crack tip
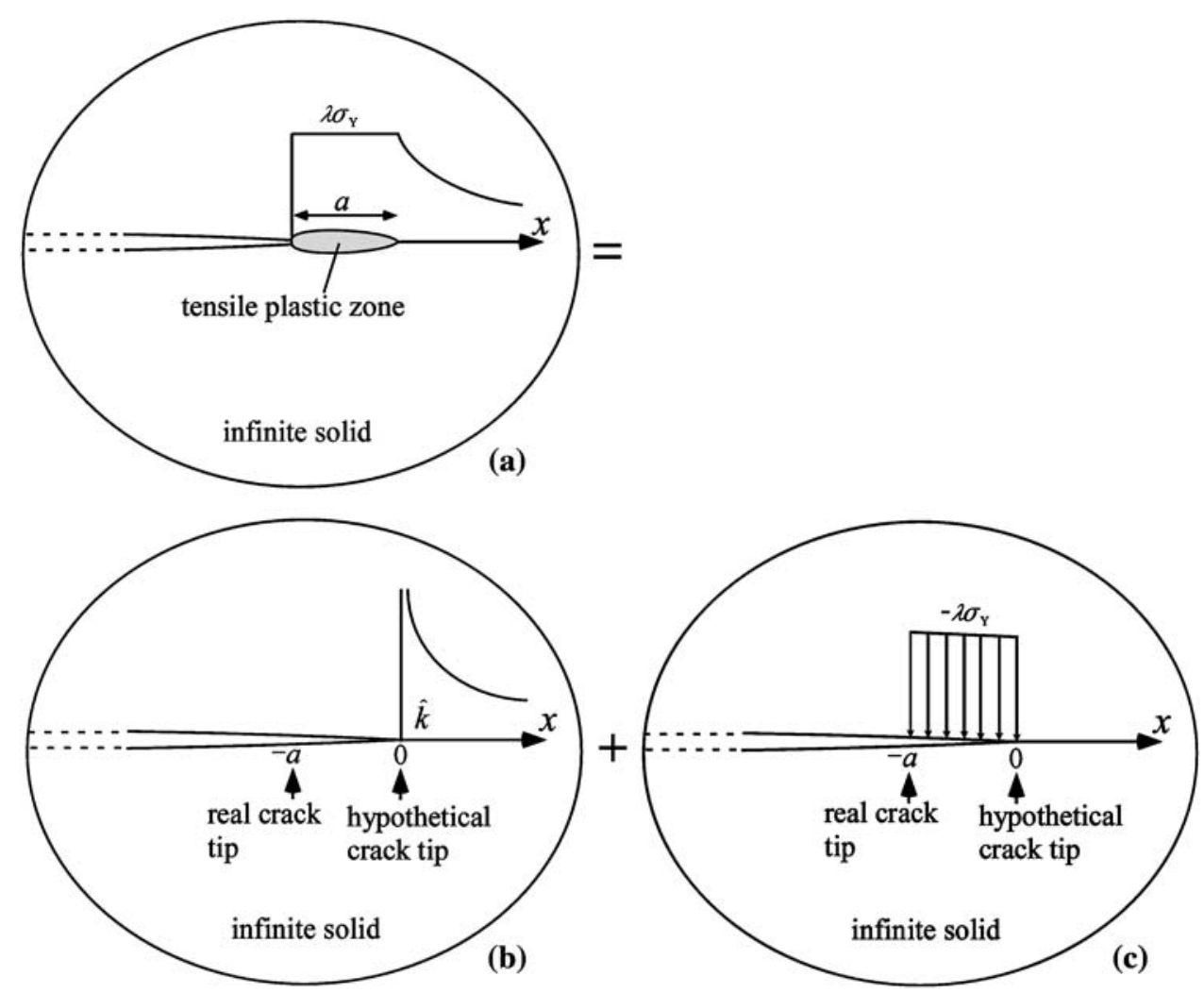
the auxiliary boundary value problem $[3,7]$ corresponding to the maximum load. Introducing the condition that the sum of the stress intensity factors of the cracks (b) and (c) vanishes due to no stress singularity at the hypothetical crack tip of the original problem, the plastic zone size, $a$, is obtained as

$a=\pi k_{\max }^{2} /\left\{8 \lambda^{2} \sigma_{\mathrm{Y}}^{2}-\pi\left(b_{\max }+2 \bar{k}_{\max }\right) k_{\max }\right\}$,

which considerably simplify the calculation procedure. The crack opening displacement at the maximum load, $v_{\max }(x)$, is given by

$v_{\max }(x)=\frac{2 \sqrt{2(-x)} k_{\max }}{E^{\prime} \sqrt{\pi}}-\frac{2 \lambda \sigma_{\mathrm{Y}}}{\pi E^{\prime}} \int_{0}^{a} \ln \left|\frac{\sqrt{\xi}+\sqrt{-x}}{\sqrt{\xi}-\sqrt{-x}}\right| \mathrm{d} \xi$,

where

$E^{\prime}= \begin{cases}E & \text { for plane stress } \\ E /\left(1-v^{2}\right) & \text { for plane strain, }\end{cases}$

and $E$ is the Young's modulus and $v$ is the Poisson ratio. It should be noted that the origin of the orthogonal coordinate system has been shifted to the hypothetical crack tip. The lengths of the bar elements in the tensile plastic zone, $l_{i}$ $(i=1, \ldots, k)$, are determined as

$l_{i}=v_{\max }\left(x_{i}\right) /\left(1+\lambda \sigma_{\mathrm{Y}} / E^{\prime}\right)$.

When the load is decreased to the minimum load, a compressive plastic zone is generated at the crack tip, and the contact may occur between the crack surfaces as illustrated in Fig. 8a. Similar to the previous problem, this problem can be considered as a superposition of the problems illustrated in Fig. 8b and c, where Fig. 8b shows the semi-infinite crack having stress intensity factor, $\widehat{k}_{\min }$, and Fig. $8 \mathrm{c}$ shows the semi-infinite crack subjected to internal and contact stresses. The stress intensity factor, $\hat{k}_{\min }$, is given by

$\hat{k}_{\min }=k_{\min }+\left\{b_{\min } / 2+\bar{k}_{\min }\right\} a *$,

where $k_{\min }$ and $b_{\text {min }}$ are the crack tip stress parameters, and $\bar{k}_{\min }$ is the parameter representing the effect of the finite boundary, respectively corresponding to the minimum load at the real crack tip, and $a^{*}$ is the length of the tensile plastic zone generated by previous load cycles. In the case where overload effects can be disregarded, the size, $a^{*}$, may coincide with that of the current plastic zone, $a$.

The crack opening displacement at the minimum load, $v_{\min }(x)$, is given by

$v_{\min }\left(x_{i}\right)=\frac{2 \sqrt{2\left(-x_{i}\right)} k_{\min }}{E^{\prime} \sqrt{\pi}}-\sum_{j=1}^{n} \sigma_{j} v\left(x_{i}, x_{j}\right)$,

where $\sigma_{j}$ is the uniform stress acting on the $j$ th bar element. The quantity $v\left(x_{i}, x_{j}\right)$ is the crack opening displacement at $x_{i}$ when a uniform unit stress acts on the crack-surface interval, $\left[b_{j}, b_{j+1}\right]$, and it is given by
Fig. 8 Superposition at the minimum load: a original problem, b semi-infinite crack having stress intensity factor, $\widehat{k}_{\text {min }}$, and $\mathbf{c}$ semi-infinite crack subjected to internal stress
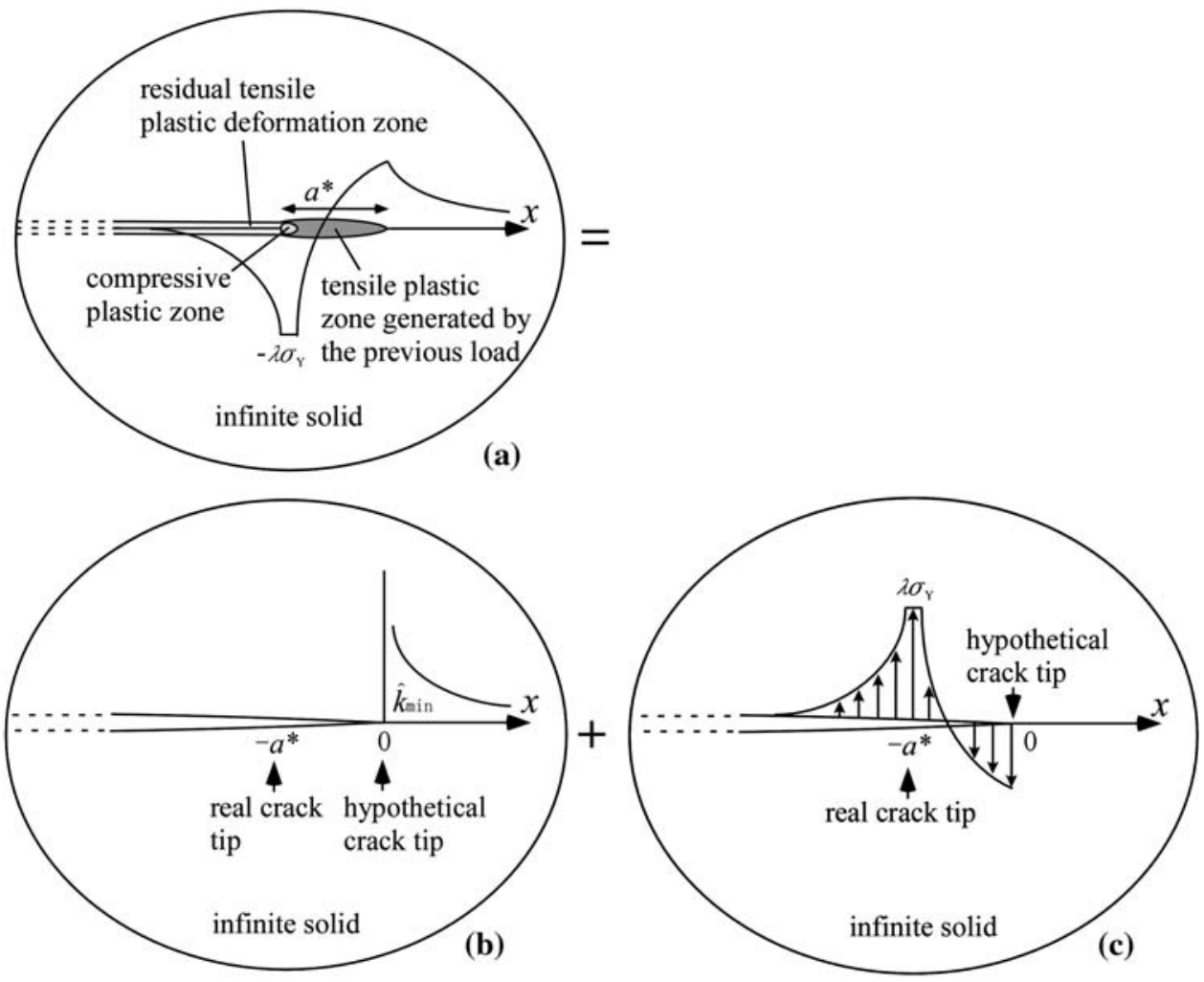
$v\left(x_{i}, x_{j}\right)=\frac{2}{\pi E^{\prime}} \int_{-b_{j}}^{-b_{j+1}} \ln \left|\frac{\sqrt{\xi}+\sqrt{-x_{i}}}{\sqrt{\xi}-\sqrt{-x_{i}}}\right| \mathrm{d} \xi$.

If an element remains elastic, the displacement of the bar element coincides with the crack opening displacement so that the following relation should hold

$v_{\min }\left(x_{i}\right)=\left(1+\sigma_{i} / E^{\prime}\right) l_{i}$.

By substituting Eq. 10 into Eq. 12, we obtain

$\frac{2 \sqrt{2\left(-x_{i}\right)} \hat{k}_{\min }}{E^{\prime} \sqrt{\pi}}-\sum_{j=1}^{n} \sigma_{j} v\left(x_{i}, x_{j}\right)=\left(1+\sigma_{i} / E^{\prime}\right) l_{i}$.

Equation 13 becomes

$$
\begin{aligned}
\sigma_{i}= & \left\{\frac{2 \sqrt{2\left(-x_{i}\right)} \hat{k}_{\min }}{E^{\prime} \sqrt{\pi}}-\sum_{\substack{j=1 \\
j \neq i}}^{n} \sigma_{j} v\left(x_{i}, x_{j}\right)-l_{i}\right\} / \\
& \left\{\frac{l_{i}}{E^{\prime}}+v\left(x_{i}, x_{i}\right)\right\},
\end{aligned}
$$

where Eq. 14 can be solved by Gauss-Seidel iterative method with the following constraints:

for the stresses of bar elements in the real crack region $\left(x_{i}<-a^{*}\right)$ if $\sigma_{i}>0, \quad$ set $\sigma_{i}=0$, and

if $\sigma_{i}<-\lambda \sigma_{\mathrm{Y}}, \quad$ set $\sigma_{i}=-\lambda \sigma_{\mathrm{Y}}$

for the stresses of bar elements in the hypothetical crack region $\left(-a^{*}<x_{i}<0\right)$

if $\sigma_{i}>\lambda \sigma_{\mathrm{Y}}, \quad$ set $\sigma_{i}=\lambda \sigma_{\mathrm{Y}}$, and

if $\sigma_{i}<-\lambda \sigma_{\mathrm{Y}}, \quad$ set $\sigma_{i}=-\lambda \sigma_{\mathrm{Y}}$.

By substituting $\sigma_{j}(j=1, \ldots, n)$ into Eq. 10, the crack opening displacement at the minimum load, $v_{\min }(x)$, is obtained. Then, the length of the bar elements in the compressive plastic zone is replaced by

$l_{i}=v_{\min }\left(x_{i}\right) /\left(1-\lambda \sigma_{\mathrm{Y}} / E^{\prime}\right)$.

\subsection{Calculation of fatigue crack growth life based on $\Delta K_{\mathrm{RP}}$}

The re-tensile plastic-zone generated (RPG) load is defined as the load at which the re-tensile plastic zone initiates to develop ahead of a crack tip [9-11]. The superposition at the RPG load is illustrated in Fig. 9. In the present model, $\widehat{k}_{\mathrm{RPG}}$ is determined as the stress intensity factor at the hypothetical crack tip, at which the stress in the crack tip element ( $k$ th element) reaches $\lambda \sigma_{\mathrm{Y}}$ during the loading process. Then, the effective stress intensity range, $\Delta K_{\mathrm{RP}}$, is defined as

Fig. 9 Superposition at the RPG load: a original problem, b semi-infinite crack having stress intensity factor $\widehat{k}_{\mathrm{RPG}}$, and c Semi-infinite crack subjected to internal load
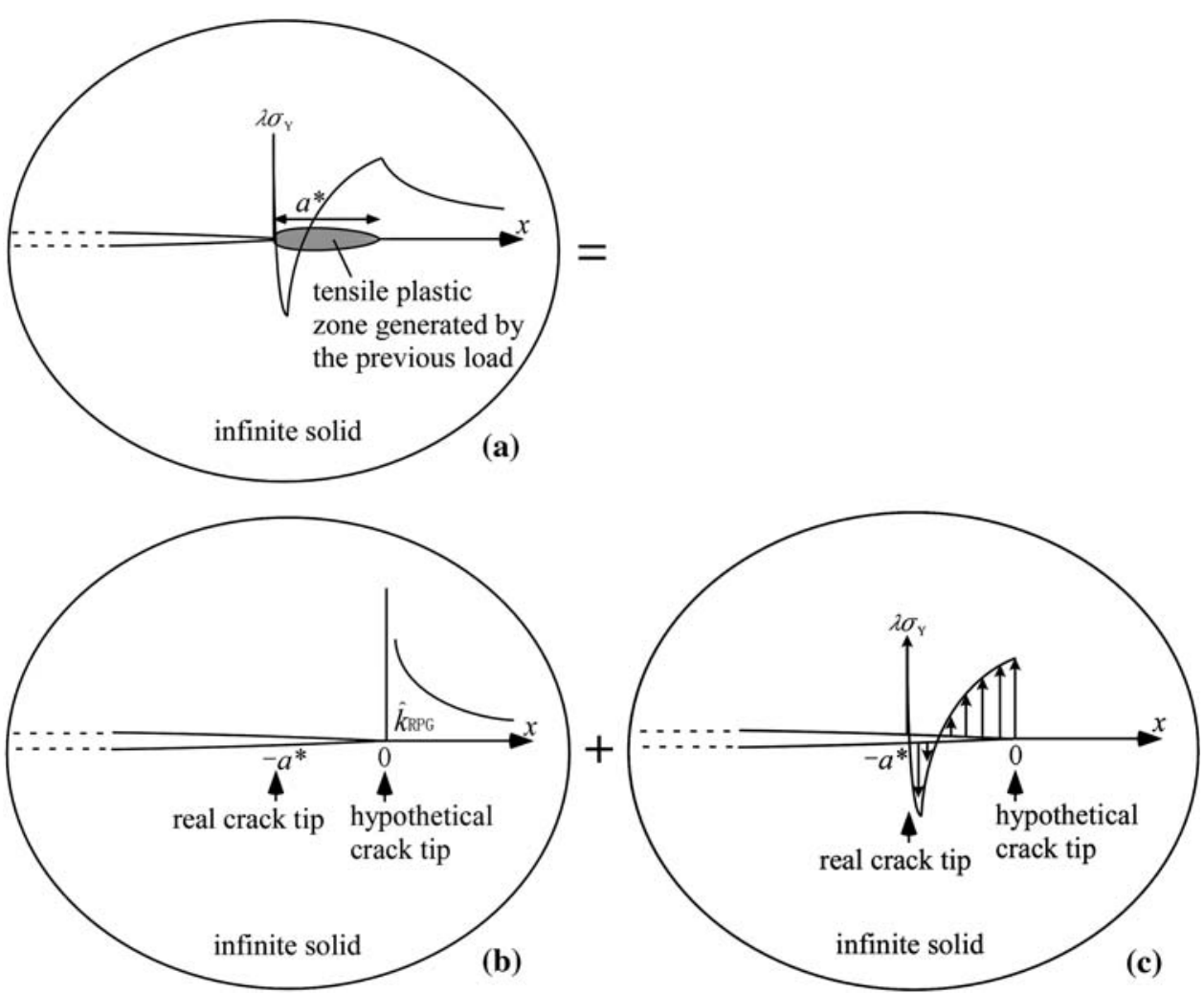


$$
\Delta K_{\mathrm{RP}}=k_{\max }\left(1-\widehat{k}_{\mathrm{RPG}} / \widehat{k}_{\max }\right) .
$$

The crack growth law based on $\Delta K_{\mathrm{RP}}$ is given by

$\mathrm{d} a / \mathrm{d} N=C\left(\Delta K_{\mathrm{RP}}\right)^{m}$,

where the material constants are given by

$C=3.514 \times 10^{-11}, m=2.692$ (SI units),

for a typical structural steel [9].

The flowchart of the crack opening and closure simulation is illustrated in Fig. 10. The crack extensional length $\Delta c$ is determined as

$\Delta c=\Delta N \times C\left(\Delta K_{\mathrm{RP}}\right)^{m}$,

where $\Delta N$ is the incremental number of cycles. In order to simulate fatigue crack growth under a completely random load sequence, $\Delta N$ should correspond to one load cycle. However, a larger value for $\Delta N$ may be employed under constant-amplitude loading or block loading for computational efficiency. In the developed program, $\Delta N$ is chosen in such a way that the loading condition does not change within these load cycles and $\Delta N$ is less the certain predefined value, which is equal to 200 in the present study.

Based on the concept of the plastic shrinkage [9-11], the length of bar elements left in the wake of advancing crack tip is determined as

$l_{i}=\frac{1}{1-\lambda \sigma_{\mathrm{Y}} / E^{\prime}}\left(v_{\min }\left(x_{i}\right)-\kappa \delta_{i}\right)$,

$\kappa=\left\{\begin{array}{ccc}\alpha(a / a *)^{n} & \text { for } & \alpha(a / a *)<1 \\ 1 & \text { for } & \alpha(a / a *) \geq 1,\end{array}\right.$,

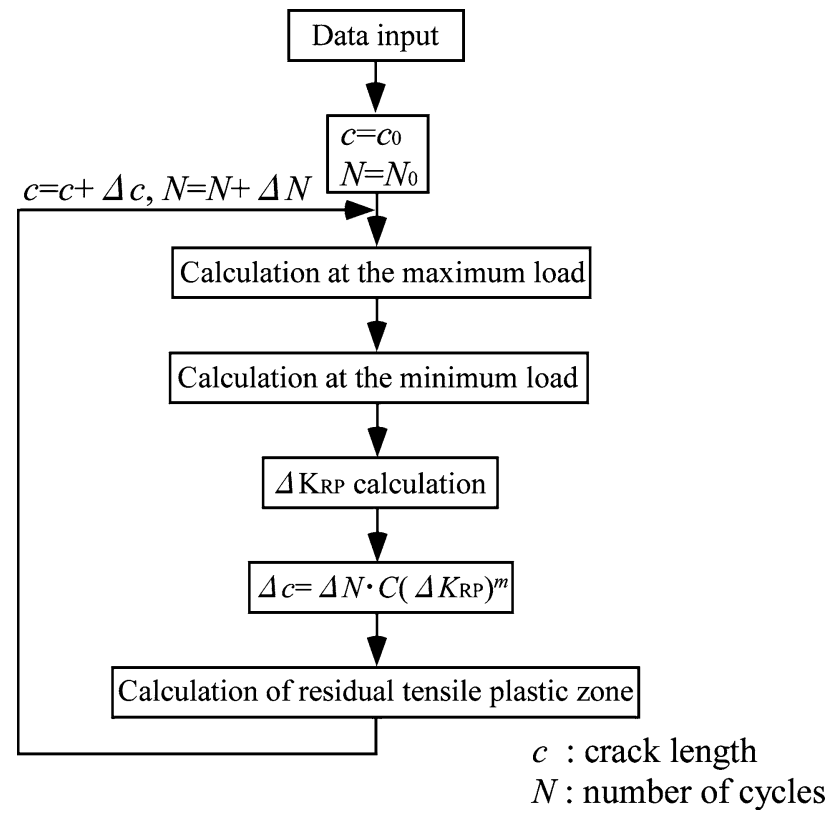

Fig. 10 Flowchart of the crack opening and closure simulation where $\delta_{i}$ is the amount of plastic shrinkage by assuming the contact stress completely released, and $\alpha$ and $n$ are the material constants. The calculation parameters for the present method and the simple method described in the previous section are summarized in Table 1.

\section{Crack growth analysis under nonconstant loading by using crack opening and closure model}

\subsection{Comparisons of simulated results with experiments}

In order to examine the proposed crack opening and closure model, we first present some comparisons of simulated and experimentally measured crack propagation lives, using the compact tension specimen illustrated in Fig. 11. The material used is SM490A specified in the JIS standard. The load histories applied in the tests are illustrated in Fig. 12a-e. All tests were performed at room temperature in atmospheric conditions and the repetition frequency was set to at $10 \mathrm{~Hz}$. The finite element model used in the simulation is illustrated in Fig. 13, where the crack propagation zone is defined in the middle of the specimen, and the surrounding structure, which is treated as a superelement, is connected on the boundary of the crack propagation zone.

Table 1 Calculation parameters

\begin{tabular}{ll}
\hline Present method & $C=3.514 \times 10^{-11}, m=2.692$ (SI units) \\
& $E=206[\mathrm{GPa}], v=0.3$, \\
& $\sigma_{\mathrm{Y}}=352[\mathrm{MPa}], \lambda=1.04, \alpha=0.1, n=0.1$ \\
Simple method & $C=1.411 \times 10^{-11}, m=2.958$ (SI units) \\
& $\left(\Delta K_{\mathrm{eff}}\right)_{\mathrm{th}}=2.58\left[\mathrm{MPa} \mathrm{m}^{1 / 2}\right]$ \\
\hline
\end{tabular}

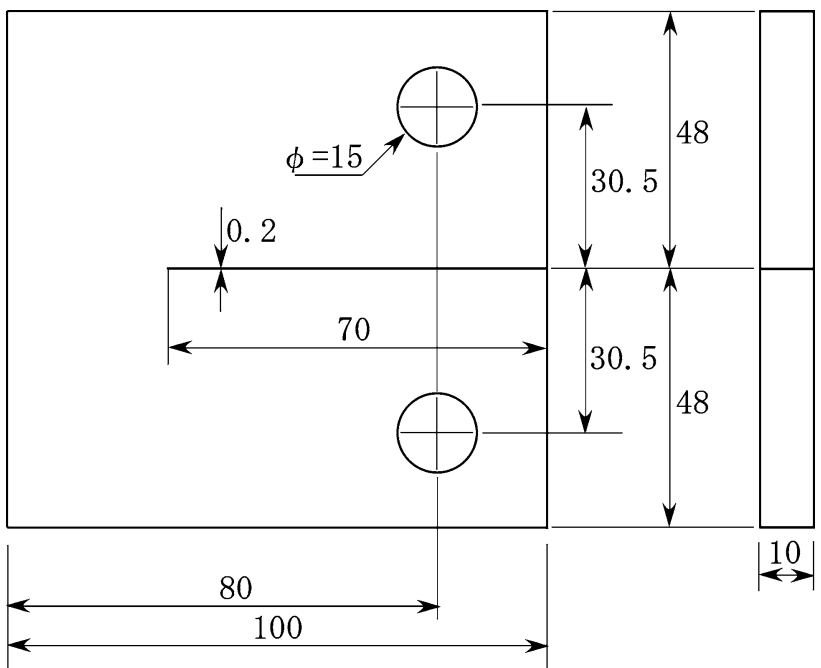

Fig. 11 Compact tension specimen 
Fig. 12 Load histories applied in the tests: a constantamplitude loading $(R=0.05)$, b constant-amplitude loading ( $R=0.3$ ), c spike loading, d step-down loading and e block loading (a)
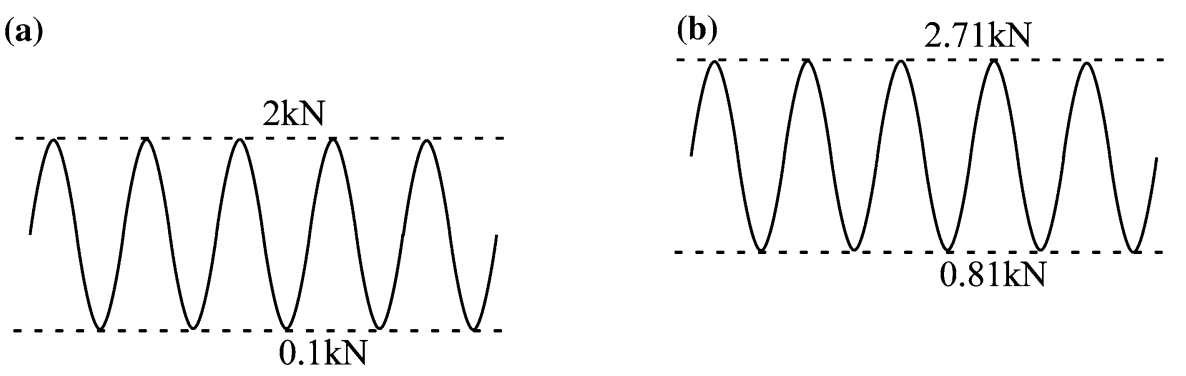

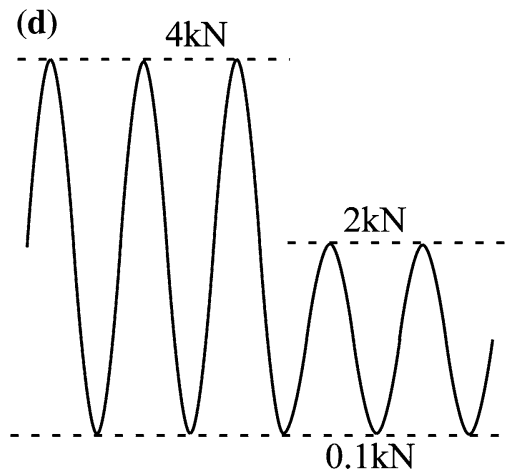

(e)
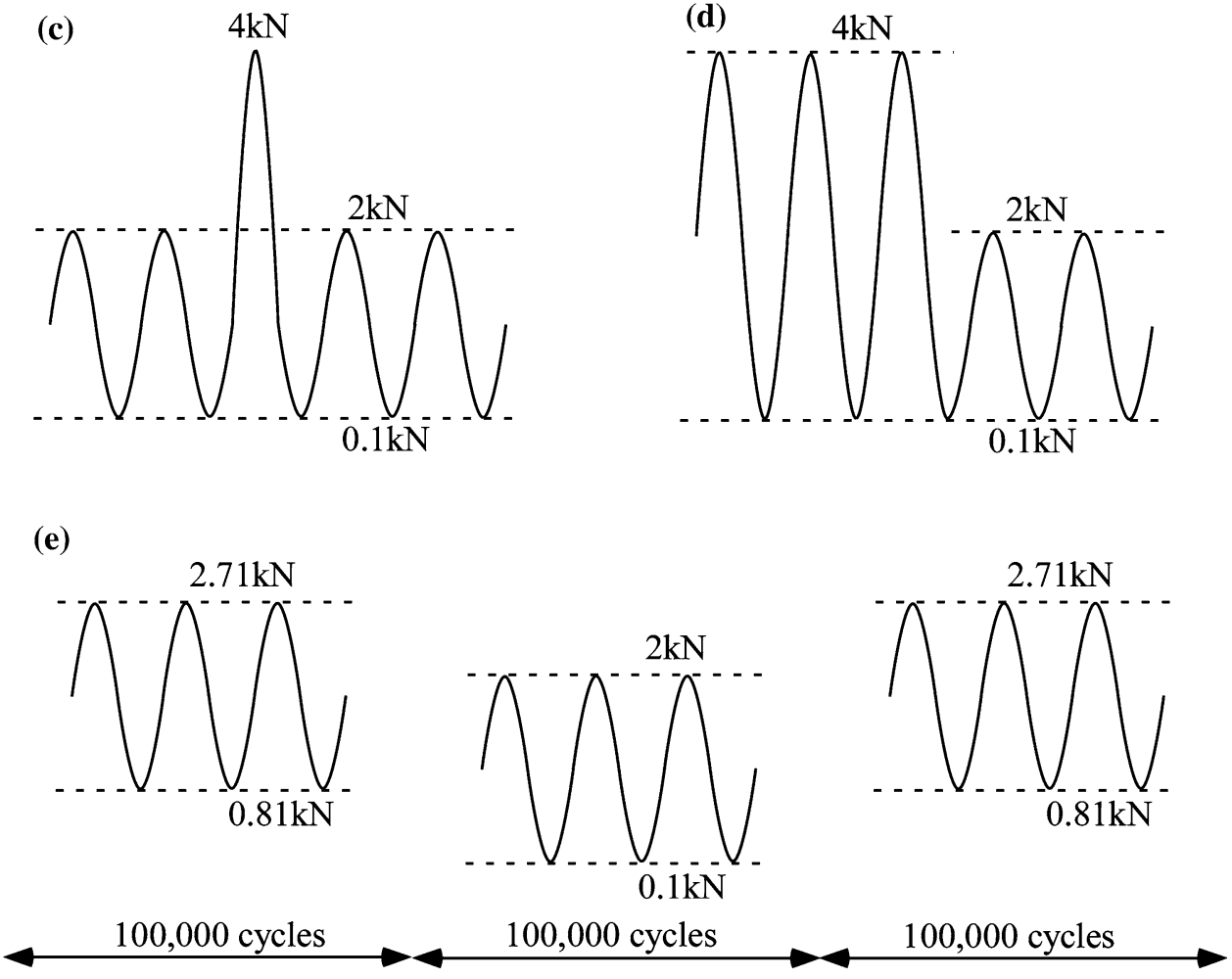

Figures 14 and 15 illustrate the crack growth curves for the constant-amplitude tests with stress ratio of 0.05 and 0.3 , respectively. The experimental and simulated results show very good agreement with each other, showing a slightly higher crack growth rate at $R=0.3$. Figure 16 illustrates the crack growth curves for the spike load test, where a spike loading of $4 \mathrm{kN}$ is applied when the crack length becomes $6.5 \mathrm{~mm}$ during the constant-amplitude load test with the stress ratio of 0.05 . A considerable retardation after the spike load is observed both in the experiment and in the simulation. It should be noted that this kind of retardation effect cannot be obtained by using the simple crack growth model, because the history of the plastic deformation ahead of a crack is not involved in the model. Figure 17 illustrates the crack growth curves for the stepdown load test, where the maximum load is decreased down to half at the crack length, $6.5 \mathrm{~mm}$. As can be seen from the experimental result, fatigue crack growth is almost arrested after the step-down load, and it is reactivated after a large number of cycles. Furthermore, Fig. 18 illustrates the crack growth curves for the block load test, where the stress ratio is periodically changed up and down every $10^{5}$ cycles retaining the same load range. In this case, the crack growth rate decreases considerably during the lower stress ratio. It has been shown that the proposed crack growth model could simulate these complicated fatigue crack growth fairly well in comparison with the experiments.

\subsection{Simulation under wave-induced loading}

In order to apply the developed program to marine structures, simulations of fatigue crack propagation in a ship structure were carried out for random sequences of water pressure. An analysis model is illustrated in Fig. 19, where it extends over 2 transverse frame spacing in length direction and 1.5 bay in width direction. In order to model the periodicity of the longitudinal stiffeners, symmetric 


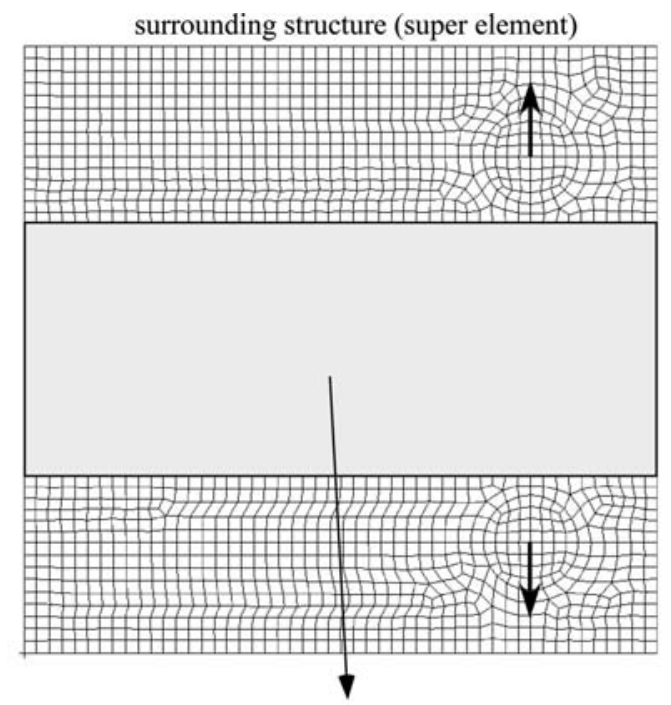

crack propagation zone

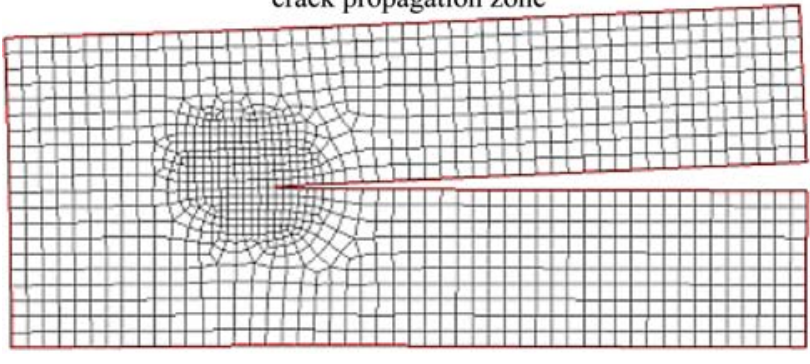

Fig. 13 Finite element model of the compact tension specimen

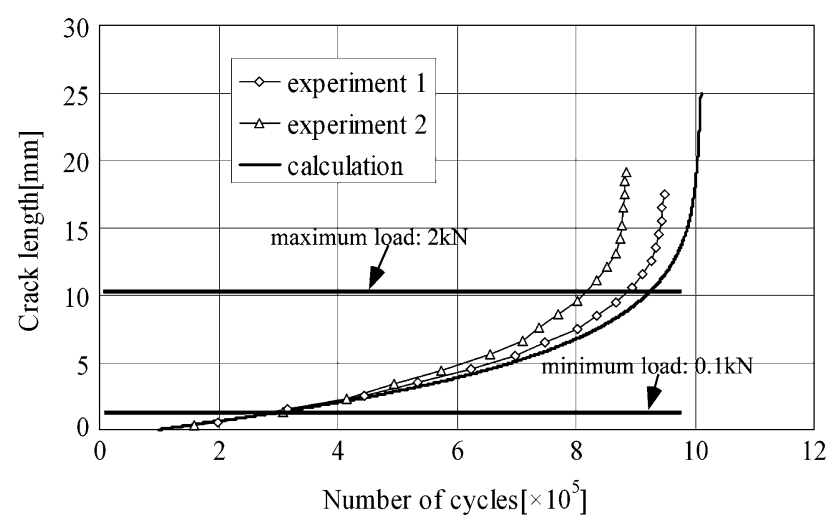

Fig. 14 Crack growth curves for the constant-amplitude load test $(R=0.05)$

conditions are prescribed along both sides of the analysis model. Uniform lateral pressure is applied on the skinplate, and the lateral displacement is restrained at the positions of the transverse girder. The longitudinal displacement is also restrained at both ends.

In Fig. 20, a finite element model is illustrated, where the crack initiation point is assumed at the intersection of the face-plate and the end of the web-stiffener. The initial crack is configured such that it has $40 \mathrm{~mm}$ width in the

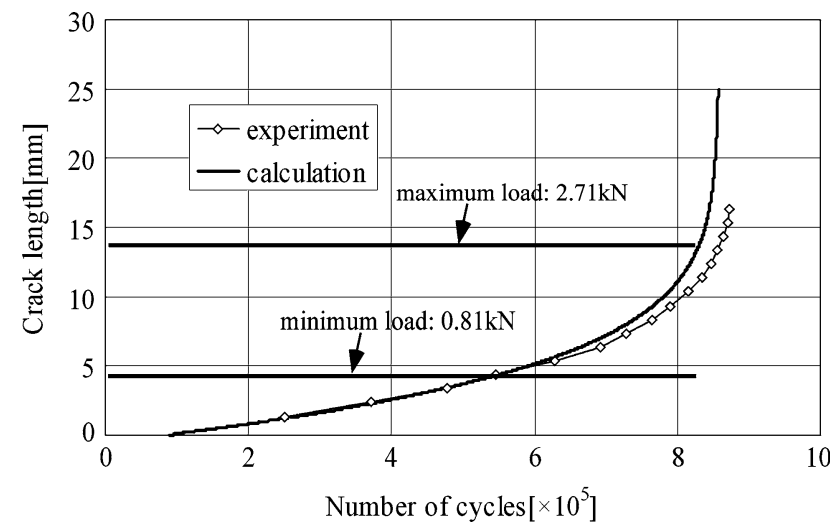

Fig. 15 Crack growth curves for the constant-amplitude load test $(R=0.3)$

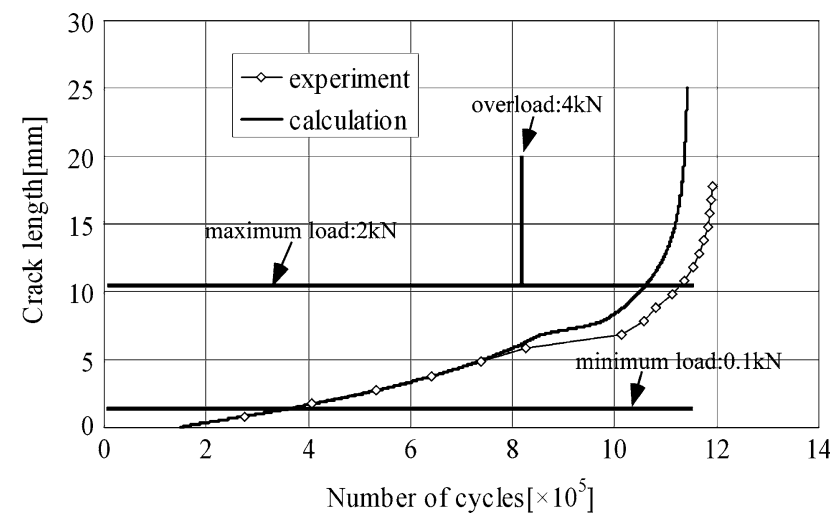

Fig. 16 Crack growth curves for the spike load test

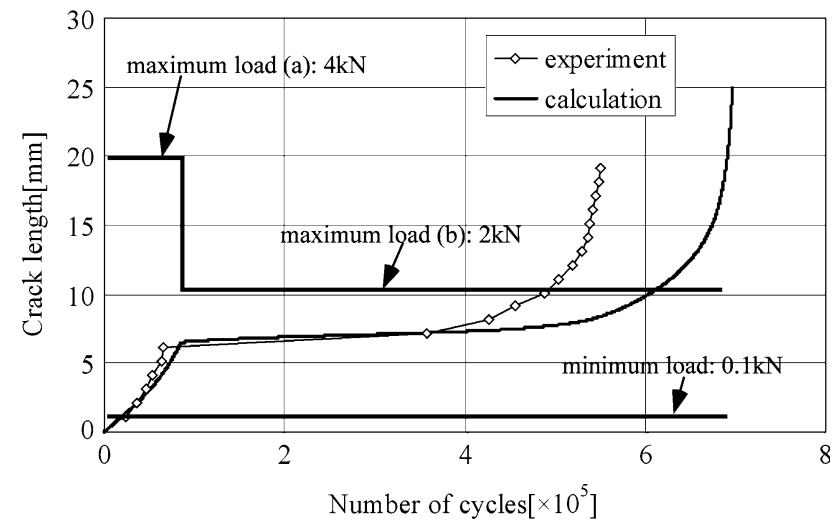

Fig. 17 Crack growth curves for the step-down load test

face-plate and $10 \mathrm{~mm}$ depth in the web-plate. In the beginning of the simulation, crack propagation domains are defined in both parts of the face-plate and the web-plate, as illustrated in Fig. 20. After the complete breakdown of the face-plate, the simulation is continued by redefining a single crack in the web-plate.

A random sequence of wave load is simulated by the so-called storm model $[12,13]$. We generated six clustered 


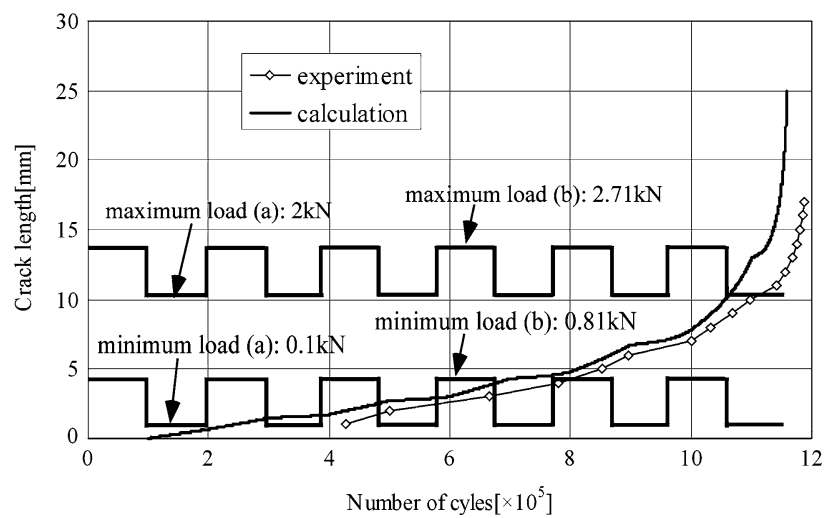

Fig. 18 Crack growth curves for the block load test

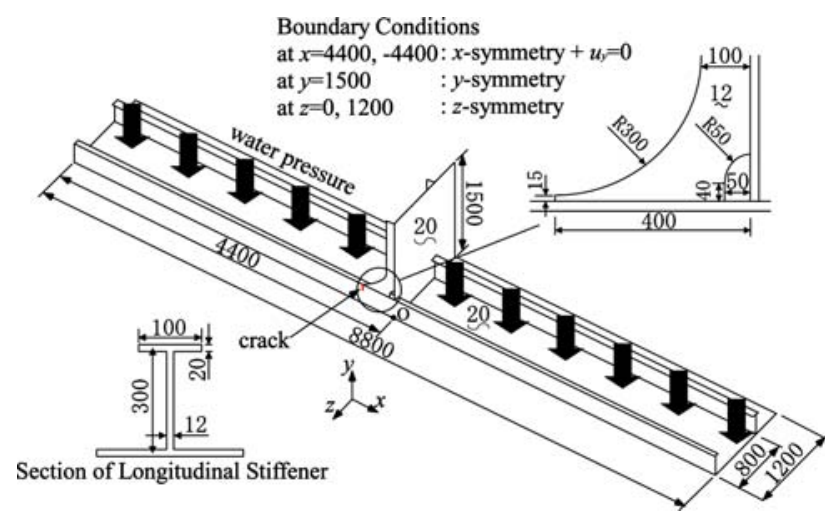

Fig. 19 Analysis model of a stiffened panel structure

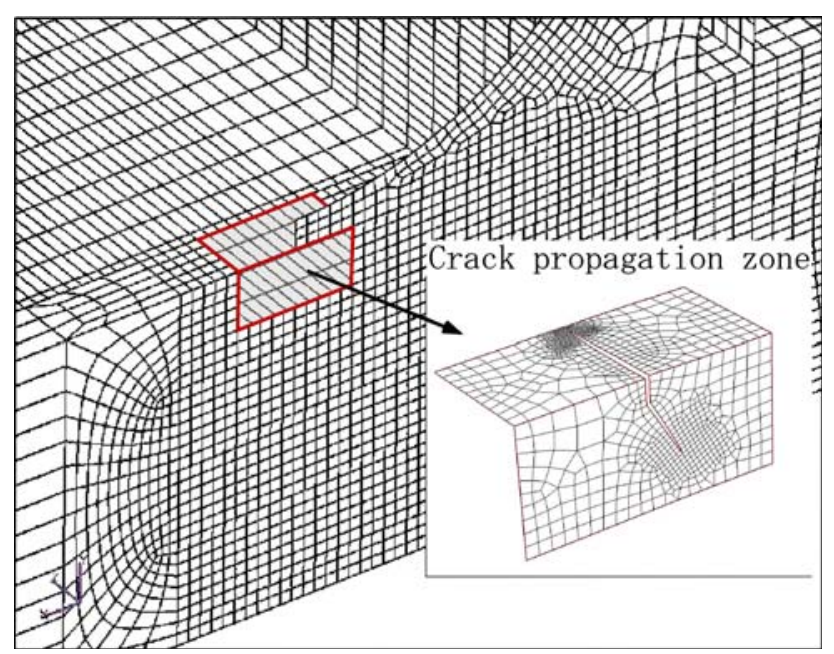

Fig. 20 Finite element model of the stiffened panel structure

load patterns A, B, C, D, E, and F as illustrated in Fig. 21, where we assumed that the maximum water pressure range is $200 \mathrm{kPa}$ in a 20 -year ship life, and the mean water pressure is $25 \mathrm{kPa}$. Each clustered loading sequence consists of 48,000 loading cycles and the probability of occurrence is defined in Table 2 so that the total spectrum of the loads satisfies the long-term distribution. These

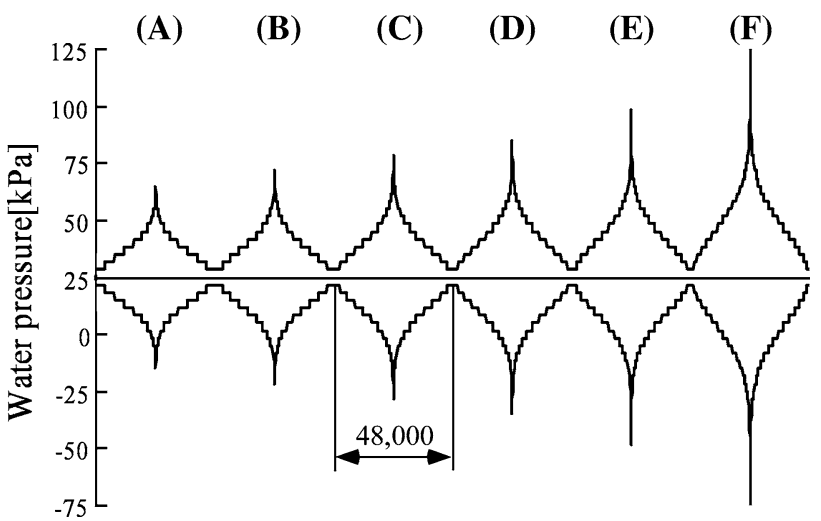

Fig. 21 Loading patterns of the water pressure

Table 2 Probability of occurrence of the clustered loads A to F

\begin{tabular}{lllllll}
\hline Storm & A & B & C & D & E & F \\
\hline Probability & $42 / 93$ & $25 / 93$ & $12 / 93$ & $7 / 93$ & $6 / 93$ & $1 / 93$ \\
\hline
\end{tabular}

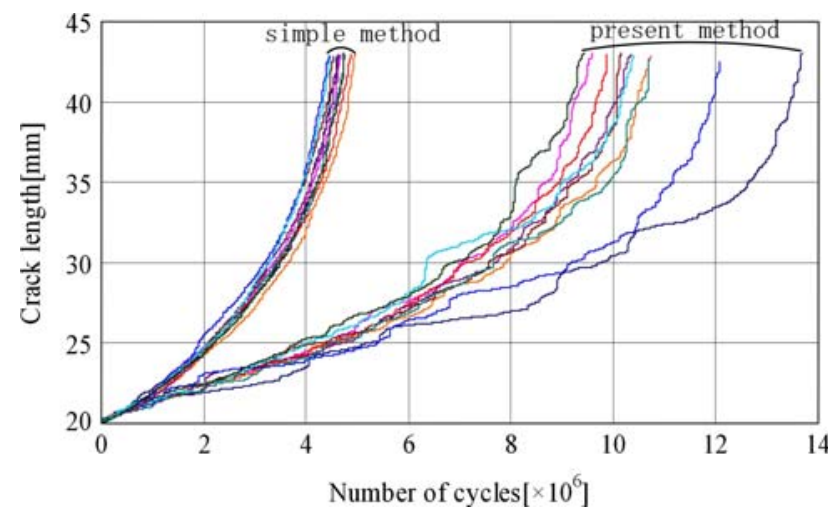

Fig. 22 Crack growth curves in the face-plate under wave-induced loading

clustered loads are applied by random sequences based on the probability of occurrence shown in Table 2 .

In Fig. 22, the simulated crack growth curves in the face-plate are illustrated, where the simulations were conducted ten times in order to compare the variation of fatigue lives with respect to the loading sequences. It is noted that the proposed crack growth model gives a considerably (from twice to three times) longer fatigue crack propagation lives in comparison with those evaluated by the simple model. Also, we can see that the variation of fatigue lives due to the random loading is remarkably wider than those calculated by the simple model. This difference can be explained by the retardation of fatigue crack growth after the application of high stress amplitude as exemplified in the previous subsection.

If we examine the detailed crack propagation behavior in the range of the first 800,000 cycles (Fig. 23), we can 
clearly observe the acceleration followed by the retardation in the present result. This should be contrasted with that obtained by using the simple Paris law. Figure 24 illustrates the variation of the effective stress intensity range ratio obtained by the proposed crack growth model, where the effective stress intensity range ratio, $\tilde{U}$, is defined by

$\tilde{U}=\Delta K_{\mathrm{RP}} / \Delta K$.

As can be seen from Fig. 24, the effective stress intensity range ratio considerably decreases after the application of the high level clustered loads. These results may imply that the conventional method for fatigue life assessment may estimate too conservative fatigue life for a ship structure.

\subsection{Investigation of fatigue crack growth under various loading conditions}

The concept of the equivalent load range is often used in the assessment of fatigue lives of structures under variableamplitude loading, where the equivalent load range, $\Delta P_{\text {eq }}$, is given by

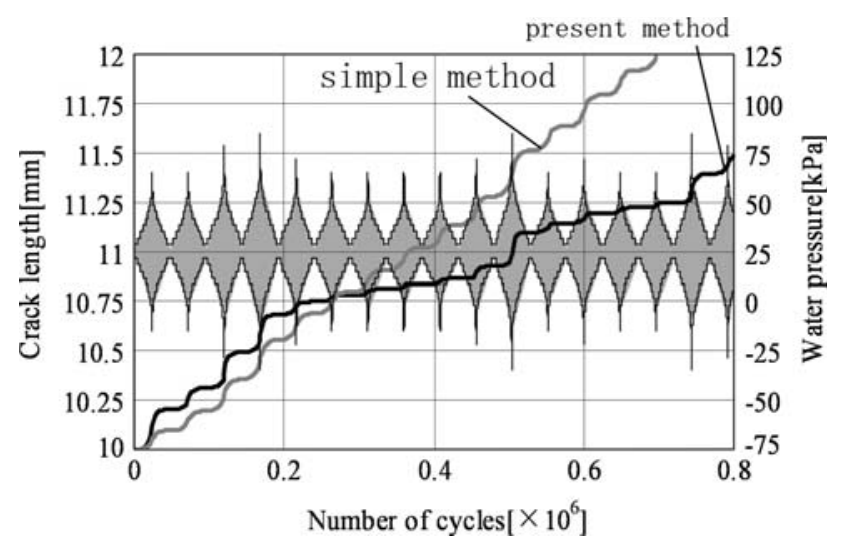

Fig. 23 The effect of high-level clustered loads on crack propagation in the face-plate

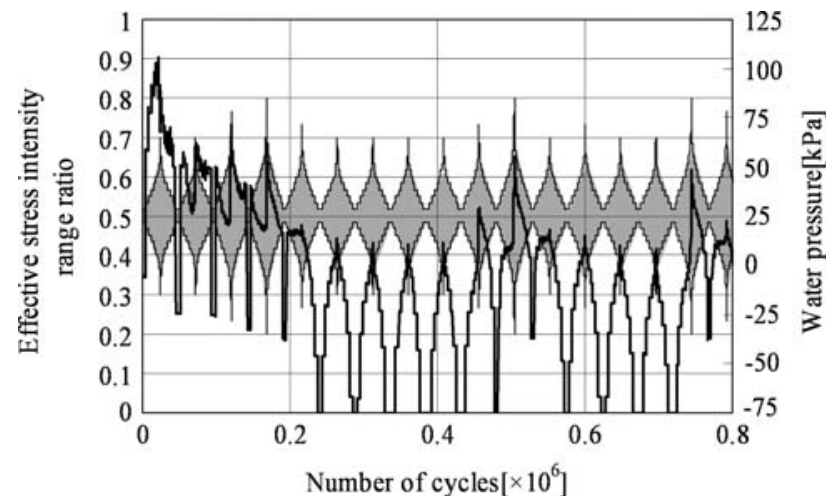

Fig. 24 The effect of high-level clustered loads on the effective stress intensity range ratio in the face-plate
$\Delta P_{\mathrm{eq}}=\sqrt[m]{\sum\left(\Delta P_{i}^{m} \times n_{i}\right) / \sum n_{i}}$,

where $\Delta P_{i}$ is the load range, $n_{i}$ is the corresponding number of cycles and $m$ the coefficient in the Paris law. Based on Eq. 22, we obtained an equivalent load range $\Delta P_{\text {eq }}=38 \mathrm{kPa}$, corresponding to the water pressure loading applied in 20 years' of storms, where we used $m=2.692$. The simulated crack growth curves in the faceplate are illustrated in Fig. 25. It is found that the crack growth curve calculated by the present method is almost in accordance with the result calculated by the simple method.

Next, we examined the effect of the load sequences, where the loading sequence of the storm model is reordered in such a way that the load range gradually increases. The simulated crack growth curves are illustrated in Fig. 26, where the simple and present methods give almost the same crack growth lives. From these results, it is found that simple estimates may give almost the same results as the proposed method without the retardation due to overload.

The simulated crack growth curves for various loading conditions are compared in Fig. 27. It is found that the

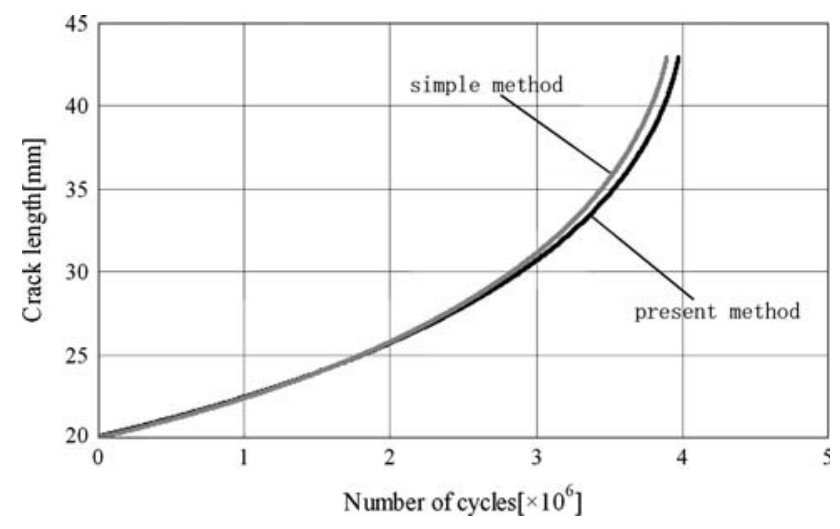

Fig. 25 Crack growth curves in the face-plate under the equivalent load range

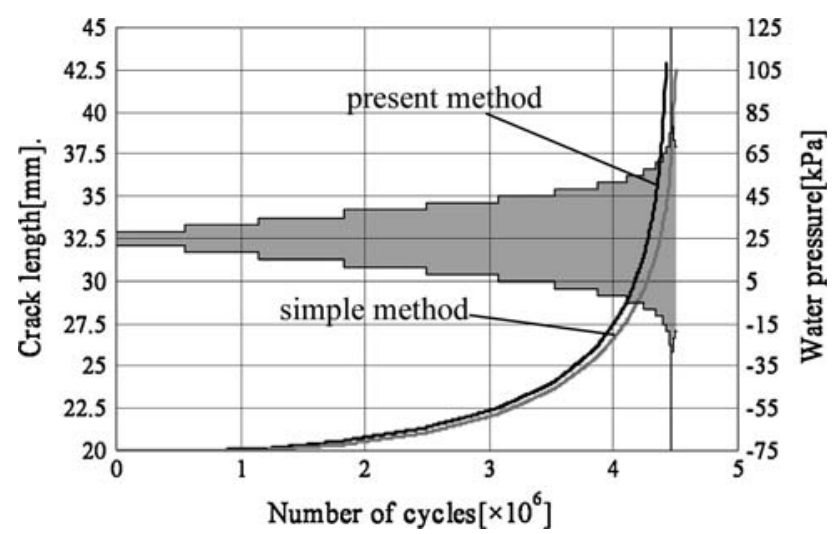

Fig. 26 Crack growth curves in the face-plate under the gradually increasing load range 


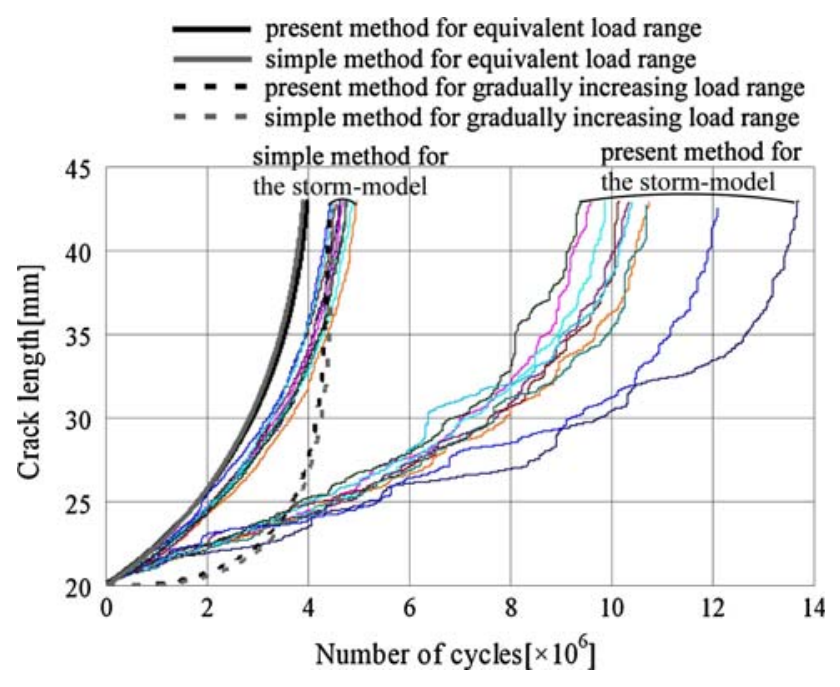

Fig. 27 Comparison of crack growth curves for each loading condition

equivalent load range or the gradually increasing load range give almost the same fatigue lives as those obtained by the simple crack growth model. In order to obtain fatigue lives of structures under random load sequences, it may be too conservative to use the simple method with the equivalent load range.

\section{Conclusions}

In the present paper, a crack opening and closure model is presented utilizing the crack tip stress field parameters evaluated by finite element analyses. In order to show an application of the proposed program for marine structures, simulations of fatigue crack propagation in a ship structure are carried out under wave-induced load sequences. If we compare the present results with the conventional ones, the present method predicts the fatigue crack propagation life to be considerably longer, with wider variations under random loading conditions. In such cases, in order to obtain relatively conservative fatigue lives of structures, it may be possible to apply the simple crack growth law with the use of an equivalent load range, but the results may be too conservative. Combined with appropriate stress monitoring and periodic inspection, the proposed fatigue crack propagation system, which is based on the precise simulation of crack paths and crack opening and closure near a crack tip, may lead to a comprehensive strategy for fatigue crack management in marine structures.

Acknowledgments This work has been supported in part by the Program for Promoting Fundamental Transport Technology Research (Project No. 2001-03) from the Japan Railway Construction, Transport and Technology Agency (JRTT), and by a Grant-in-Aid for Scientific Research (No. A-1720608600) from the Ministry of Education, Science and Culture to Yokohama National University. The authors are grateful for their support.

\section{References}

1. Sumi Y, Mohri M, Kawamura Y (2005) Computational prediction of fatigue crack paths in the ship structural details. Fatigue Fract Eng Mater Struct 28(1):107-115

2. Sumi Y, Mohri M, Okawa T (2004) Simulation-based fatigue crack management for ship structural details. 9th symposium on practical design of ships and other floating structures, LubeckTravemuende, Germany. pp 855-861

3. Okawa T, Sumi Y, Mohri M (2006) Simulation-based fatigue crack management of ship structural details applied to longitudinal and transverse connections. Mar Struct 19(4):217-240

4. Sumi Y (1998) Fatigue crack propagation and computational remaining life assessment of ship structures. J Mar Sci Technol 3:102-112

5. Sumi Y, Chen Y, Hayashi S (1996) Morphological aspects of fatigue crack propagation. Part I. Computational procedure. Int J Fract 82:205-220

6. Sumi Y, Chen Y, Wang ZN (1996) Morphological aspects of fatigue crack propagation. Part II. Effect of stress biaxiality and welding residual stress. Int J Fract 82:221-235

7. Sumi Y, Wang ZN (1998) A finite-element simulation method for a system of growing cracks in a heterogeneous material. Mech Mater 28:197-206

8. Newman JC Jr (1981) A crack-closure model for predicting fatigue crack growth under aircraft spectrum loading. ASTM STP 748:53-84

9. Toyosada M, Niwa T (2001) Fatigue life prediction of steel structures, Kyoritsu publishing (in Japanese)

10. Toyosada M, Gotoh K, Niwa T (2004) Fatigue crack propagation for a through thickness crack: a crack propagation law considering cyclic plasticity near the crack tip. Int J Fatigue 26:983-992

11. Toyosada M, Gotoh K, Niwa T (2004) Fatigue life assessment for weld structures without initial defects: an algorithm for predicting fatigue crack growth from a sound site. Int J Fatigue 26:993-1002

12. Tomita Y, Hashimoto K, Nagamoto R, Kawabe H, Fukuoka T (1995) Stochastic characteristic of long term distribution of waveinduced loading and simulation method for fatigue strength analysis of ship structural member (in Japanese). J Soc Nav Archit Jpn 177:381-390

13. Tomita Y, Hashimoto K, Osawa N, Terai K, Wang Y (2002) Study on fatigue design load for ships based on crack growth analysis, ASTM STP, n 1439, Fatigue testing and analysis under variable loading conditions, pp 420-434

14. Kawamura Y, Mu Y, Sumi Y (1999) Development of an automatic quadrilateral mesh generator for the simulation of curved crack growth. Transaction of the Japan Society of Computational Engineering, Paper No.19990024

15. Yamamoto Y, Tokuda N (1973) Determination of stress intensity factors in cracked plate by the finite element method. Int J Numer Method Eng 6:427-439

16. Sumi Y, Nemat-Nasser S, Keer LM (1983) On crack branching and curving in a finite body. Int J Fract 21:67-79, Erratum (1984) Int J Fract 24:159

17. Sumi Y (1986) A note on the first order perturbation solution of a straight crack with slightly branched and curved extension under a general geometric and loading condition. Eng Fract Mech 24(3):479-481

18. Goldstein RV, Salganik RL (1974) Brittle fracture of solids with arbitrary cracks. Int J Fract 10:507-523

19. Kato A, Kurihara M, Kawahara M (1983) An expression of fatigue crack propagation rates under wide ranged stress ratios (in Japanese). J Soc Nav Archit Jpn 153:336-343 